\title{
Minireview
}

\section{HMG CoA reductase inhibitors (statins) to treat Epstein-Barr virus-driven lymphoma}

\author{
J Cohen*,I \\ 'Laboratory of Clinical Infectious Diseases, Medical Virology Section, National Institute of Allergy and Infectious Diseases, National Institutes of Health, \\ BIdg. I0; Rm. I IN228, 10 Center Drive, MSC 1888, Bethesda, MD 20892, USA
}

While statins have been highly effective for lowering serum cholesterol and reducing the incidence of coronary events, they have multiple other effects. Certain statins block the interaction of adhesion molecules that are important for cell-cell interactions including those between EBV-transformed B cells. These same statins inhibit NF- $\kappa$ B activation in the cells and induce apoptosis of transformed B cells. Studies in severe combined immunodeficiency mice show that simvastatin delays the development of EBV-lymphomas in these animals. These statins might be considered for the treatment of EBV-lymphomas in selected patients. British Journal of Cancer (2005) 92, I593- 1598. doi: I0.1038/sj.bjc.660256I www.bjcancer.com

Published online 26 April 2005

(c) 2005 Cancer Research UK

Keywords: statin; Epstein-Barr virus; apoptosis; NF- $\kappa$ B; lymphoma

\section{BIOLOGY OF EPSTEIN-BARR VIRUS}

Epstein-Barr virus (EBV) infects over $90 \%$ of the world's population. Most infections occur in young children and are asymptomatic or result in nonspecific symptoms. Infection of adolescents and young adults can result in infectious mononucleosis. Epstein-Barr virus is associated with a number of malignancies including Burkitt lymphoma, nasopharyngeal carcinoma, Hodgkin's disease, T-cell lymphomas, and lymphoproliferative disease in stem cell and organ transplant recipients (Cohen, 2000).

Epstein-Barr virus infects resting B lymphocytes and transforms them so that they proliferate indefinitely (Kieff, 2001). Of the nearly 100 viral proteins encoded by the genome, nine are expressed during transformation in vitro. These nine latencyassociated proteins are the EBV nuclear antigens (EBNA-1, -2, -3A, $-3 B,-3 C$, and $-\mathrm{LP}$ ) and the EBV latent membrane proteins (LMP-1, LMP2-A, LMP-2B). Epstein-Barr virus-transformed B cells grow in tight clumps in vitro.

Epstein - Barr virus gene expression differs among malignancies associated with the virus. Epstein-Barr virus-positive Burkitt lymphoma tissue shows expression of EBNA-1, but not the other latency-associated proteins (Rowe et al, 1987). Hodgkin's disease tissues show expression of EBNA-1, LMP-1, and LMP-2 (Deacon et al, 1993) while nasopharyngeal carcinoma (Fahraeus et al, 1988) and T-cell lymphomas (Anagnostopoulos et al, 1992) express EBNA-1, LMP-2 and have variable expression of LMP-1. Epstein Barr virus lymphomas in immunocompromised persons generally show expression of each of the nine latency associated proteins. Epstein-Barr virus proteins expressed during latency may serve as targets for novel chemotherapeutic agents. While the treatment for some EBV-associated malignancies has improved in recent years,

*Correspondence: Dr Jl Cohen; E-mail: jcohen@niaid.nih.gov Received 3 November 2004; revised 7 March 2005; accepted 9 March 2005; published online 26 April 2005 newer approaches to therapy are needed. Here, we describe the possible use of certain statins in the treatment of EBV-driven lymphomas.

\section{THE ROLE OF EBV LMP-1 IN ONCOGENESIS}

LMP-1 is the latency-associated protein that has been most directly linked to oncogenesis by EBV. Expression of LMP-1 in B cells of transgenic animals results in B-cell lymphomas (Kulwichit et al, 1998). LMP-1 upregulates the expression of a large number of proteins on the surface of virus-infected $B$ cells, including intercellular adhesion molecules (ICAM)-1, leucocyte function antigen 1 (LFA-1), and LFA-3 (Figure 1A) (Peng and Lundgren, 1992). Expression of LMP-1 in lymphoma cells induces clumping of the cells (Wang et al, 1990).

LMP-1 acts as a functional homologue of a constitutively active form of CD40. LMP-1 oligomerises on the surface of virus-infected cells and binds to the tumour necrosis factor receptor-associated factors (TRAFs) 1,2,3 and 5, TRADD, RIP, and Janus-activated kinase (JAK) 3 (Devergne et al, 1996) (Figure 2A). The interaction of LMP-1 with these proteins results in activation of NF- $\kappa \mathrm{B}, \mathrm{c}$-jun $\mathrm{N}$-terminal kinase, signal transducers and activators of transcription (STATs), the p38 MAP kinase pathway, and stress-activated kinases. This results in constitutive B-cell proliferation and inhibition of apoptosis. LMP-1 also interacts with p85 to activate the phosphatidylinositol 3-kinase/Akt pathway and increase cell survival (Dawson et al, 2003). LMP-1 upregulates several other antiapoptotic proteins including A20, Mcl-1, bcl-2, and bfl-1.

Epstein-Barr virus-associated B-cell lymphomas in humans show activation of NF- $\kappa \mathrm{B}$, and LMP-1 colocalises with TRAF- 1 and TRAF-3 (Liebowitz, 1998). In addition, TRAFs 1,2 , and 3 and $\mathrm{NF}-\kappa \mathrm{B}$ are expressed in post-transplantation lymphoproliferative disorders (Ramalingam et al, 2003). Furthermore, these lesions show expression of adhesion molecules upregulated by LMP-1 including LFA-1 (Hamilton-Dutoit et al, 1993). Thus, LMP-1 is 

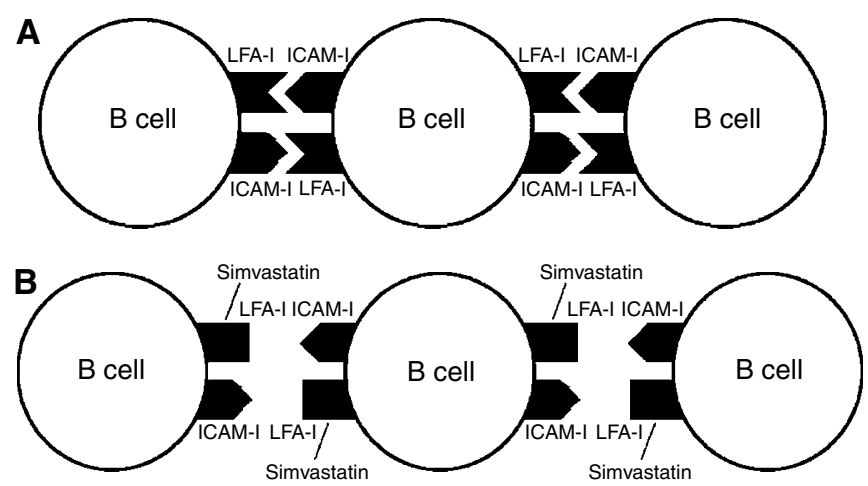

Figure I Simvastatin inhibits the interaction of LFA- I with ICAM-I on B cells. Epstein-Barr virus-transformed B cells express LFA-I and ICAM-I adhesion molecules on their surface $(\mathbf{A})$. Simvastatin binds to the I-domain of LFA-I, inducing a conformational change that inhibits the ability of LFA- I to bind to ICAM-I (B).
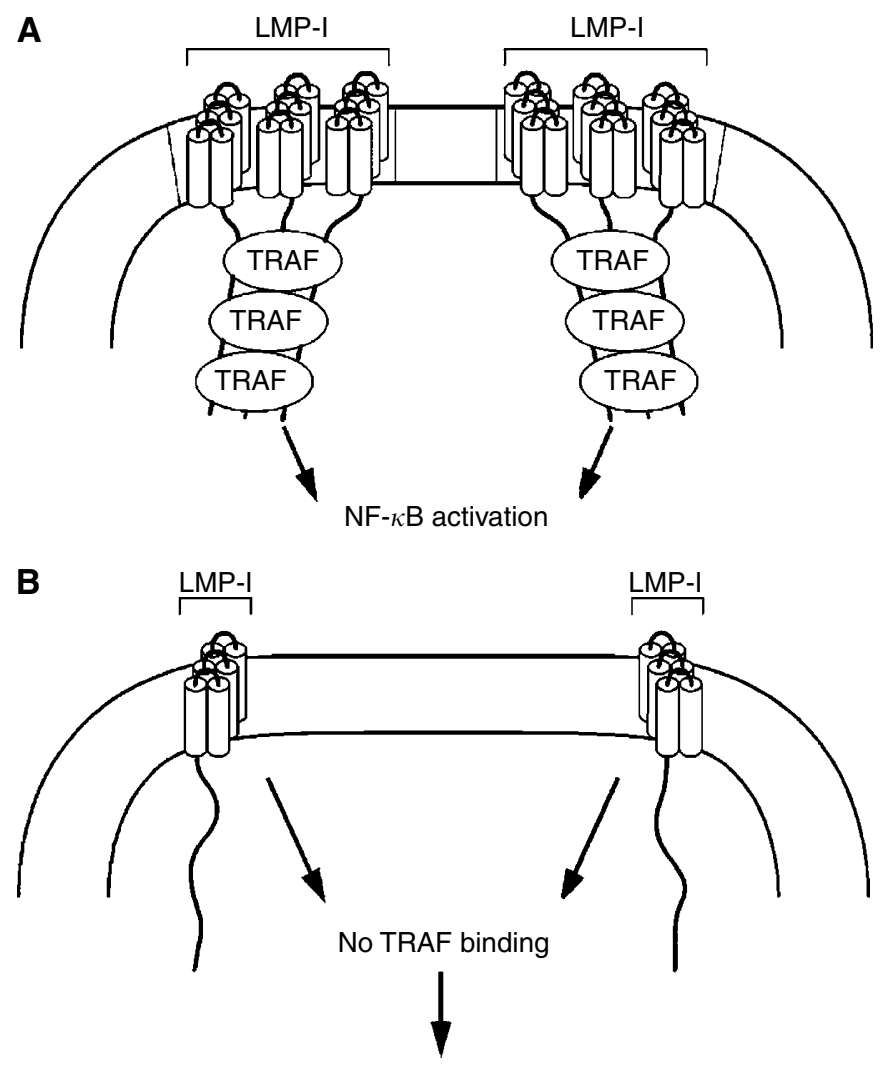

No NF- $\kappa$ B activation

Figure 2 Simvastatin inhibits NF- $\kappa$ B activation by LMP-I. Oligomerisation of LMP-I in lipid rafts on the surface of EBV-transformed $B$ cells recruits TRAFs to the cytoplasmic tail of LMP-I, which results in NF- $\kappa$ B activation and inhibition of apoptosis $(\mathbf{A})$. Simvastatin displaces LMP-I from lipid rafts resulting in absence of NF- $\kappa$ B activation and apoptosis of the cells (B).

critical for B-cell proliferation and development of lymphomas in vivo.

Treatment of EBV-transformed B cells with NF- $\kappa$ B inhibitors (e.g. I $\kappa \mathrm{B} \alpha$ mutant, Bay11-7082) has been shown to induce apoptosis of the cells (Cahir-McFarland et al, 2000, 2004). We have found that treatment of EBV-transformed cells with simvastatin also inhibits NF- $\kappa \mathrm{B}$ and induces apoptosis of EBVtransformed B cells (Katano et al, 2004).

\section{STATINS: HMG CoA REDUCTASE INHIBITORS}

Statins inhibit 3-hydroxy-3-methylglutaryl coenzyme A (HMGCoA) reductase. Six of these compounds, atorvastatin, fluvastatin, lovastatin, pravastatin, rosuvastatin, and simvastatin, are approved by the FDA for use in humans. Each of these compounds is used to treat elevated serum cholesterol. HMG-CoA reductase catalyses the conversion of HMG-CoA to mevalonate, which ultimately leads to synthesis of cholesterol. Therefore, statins reduce the level of mevalonate with a subsequent reduction in cholesterol.

Statins have a number of other activities related to their inhibition of HMG-CoA reductase (reviewed in Raggatt and Partridge, 2002). Mevalonate is a precursor for isoprenoids, including geranyl pyrophosphate and farnesyl pyrophosphate. Statins reduce the levels of these compounds. Post-translational modification of proteins by farnesylation or geranylgeranylation results in their association with cell membranes and activation (reviewed in Bellosta et al, 2000). These modified proteins include members of the nuclear laminin family, ras, inositol triphosphate 5-phosphatase, which are farnesylated, and Rho, Rac, cdc42, Rab, Rap, and G-proteins, which are geranylgeranylated. These changes have pleotrophic effects including inhibition of smooth muscle proliferation (Corsini et al, 1993), inhibition of MHC class II complexes on antigen-presenting cells (Kwak et al, 2000), increase in bone morphogenetic protein (Mundy et al, 1999), suppression of T- and B-cell responses (Kurakata et al, 1996), reduced NK cell activity (Hillyard et al, 2004), reduced synthesis of chemokines (Waehre et al, 2003), and growth arrest of certain transformed cells (Graaf et al, 2004). These effects can be reversed with the addition of mevalonate.

Certain statins have activities that are unrelated to their inhibition of HMG-CoA reductase. Kallen et al (1999) showed that lovastatin binds to the I-domain of LFA-1 and blocks its interaction with ICAM-1. LFA-1 $\left(\alpha_{\mathrm{L}} \beta_{2}\right.$ integrin) is an adhesion molecule that promotes diapedesis of leucocytes across the endothelium and is a costimulatory molecule on activated $\mathrm{T}$ cells. The I-domain of LFA-1 is separate from the site of its binding to its ligand ICAM-1. Weitz-Schmidt et al (2001) subsequently showed that simvastatin, mevastatin as well as lovastatin (but not pravastatin) can bind to LFA-1 and block its binding to ICAM-1. This interaction is independent of HMG-CoA and is not reversed by mevalonate. Simvastatin and lovastatin concentrations of $\sim 10 \mu \mathrm{M}$ are required to block these interactions; this is in contrast to the nanomolar concentrations required to inhibit HMG-CoA. A synthetic statin (LFA703) which lacks HMGCoA reductase inhibitory activity, but which has increased LFA-1 binding activity, blocks LFA-1-induced costimulation of T cells and suppresses the inflammatory response to thioglycollate in a mouse model of peritonitis.

Statins have been shown to affect replication of HIV. HIV virions have ICAM-1 on their surface, which can bind to LFA-1 on target cells and enhance virus attachment (Fortin et al, 1997). Lovastatin inhibits replication of HIV by inhibiting the interaction of ICAM-1 on virions with LFA-1 on the surface of target cells (Giguere and Tremblay, 2004). Lovastatin inhibits HIV-induced Rho GTPase activation, which is important for HIV infection of cells (del Real et al, 2004). Entry into and exit from HIV-infected cells is blocked by lovastatin and this effect can be reversed by treatment with mevalonate. Treatment of HIV-infected severe combined immunodeficiency (SCID)-hu mice or humans with lovastatin results in a reduction in HIV RNA loads and increased CD4 + T-cell counts. 


\section{SIMVASTATIN INDUCES APOPTOSIS OF EBV- TRANSFORMED B CELLS}

Treatment of EBV-transformed B cells with $\geqslant 2 \mu \mathrm{M}$ of simvastatin, atorvastatin, or lovastatin resulted in dissociation of cell clumps and death beginning 5 days after treatment with the drug (Katano et al, 2004). Cell death induced by simvastatin was due to apoptosis as demonstrated by detection of fragmented DNA.

While simvastatin induced cell death in EBV-positive Burkitt lymphoma cells (such as Akata, Mutu-1, Mutu-3, and P3HR-1 cells), EBV-negative $\mathrm{B}$ cells, and EBV-negative $\mathrm{T}$ cells, the concentration of simvastatin required to kill these cells $(\geqslant 4 \mu \mathrm{M})$ was higher than for cells transformed with EBV in vitro.

Simvastatin and lovastatin block the interaction of LFA-1 with ICAM-1, while pravastatin does not. In contrast to apoptosis of EBV-transformed B cells induced by simvastatin, treatment of these cells with up to $16 \mu \mathrm{M}$ of pravastatin did not dissociate cell clumps or induce cell death (Katano et al, 2004). In addition, antibody to LFA-1, which can activate lymphocytes (Perez et al, 2003), prevented cell death induced by simvastatin.

\section{Simvastatin displaces LMP-1 from lipid rafts and inhibits NF- $\boldsymbol{\kappa} B$}

LMP-1 is present in lipid rafts on the cell membrane (Higuchi et al, 2001). Lipid rafts are microdomains in the membrane that are rich in cholesterol and sphingolipids and are resistant to detergent extraction. They are important for signal transduction in B cells by CD40 or by immunoglobulin on the surface of the cells. The carboxy terminal domain of LMP-1 is activated when targeted to lipid rafts where it induces signalling and activation of NF- $\kappa \mathrm{B}$ mediated transcription (Kaykas et al, 2001). A mutation in one of the transmembrane domains of EBV LMP-1 results in lack of LMP1 localisation to rafts, failure to bind TRAF 3, and loss of activation of NF- $\kappa$ B (Yasui et al, 2004). Treatment of EBV-transformed B cells with $2 \mu \mathrm{M}$ simvastatin for 3 days reduced the amount of LMP-1 present in lipid rafts by $85 \%$ (Katano et al, 2004). While this effect might have been attributable to the depletion of cholesterol by the statin, it occurred at a relatively low level of simvastatin and treatment of cells with $8 \mu \mathrm{m}$ pravastatin did not result in a reduced amount of LMP-1 in rafts. Treatment of EBV-transformed B cells with $2 \mu \mathrm{M}$ simvastatin for 3 days inhibited NF- $\kappa \mathrm{B}$ activation. Cells treated with $8 \mu \mathrm{m}$ pravastatin did show reduced activation of $\mathrm{NF}-\kappa \mathrm{B}$.

Since LMP-1 also activates the phosphatidylinositol 3-kinase/ Akt pathway (Dawson et al, 2003), displacement of LMP-1 from lipid rafts may reduce activation of this pathway and inhibit survival of EBV-transformed B cells.

While LMP-2 has also been shown to be present in lipid rafts (Dykstra et al, 2001) and simvastatin might have an effect on LMP2 , the observation that LMP-2 is dispensable for B-cell transformation by EBV (Speck et al, 1999), suggests that the effect of simvastatin in killing transformed B cells is unlikely to be mediated through LMP2.

\section{Simvastatin-induced apoptosis: inhibition of NF- $\kappa \mathrm{B} v s$ inhibition of adhesion molecule interactions}

The effects of simvastatin on EBV-transformed B cells cells could be due the ability of the drug to block adhesion molecule interactions on the surface of B cells, or to displace LMP-1 from rafts and inhibit NF- $\kappa \mathrm{B}$ (Figures $1 \mathrm{~B}$ and $2 \mathrm{~B}$ ). Examination of multiple EBV-positive and EBV-negative cell lines showed that induction of cell death by simvastatin correlated best with expression of LMP-1 and activated NF- $\kappa \mathrm{B}$ in the cells prior to treatment with drug (Katano et al, 2004). Cells expressing the highest levels of LMP-1 and NF- $\kappa$ B (EBV-transformed B cells) were most susceptible to simvastatin-induced cell death; one cell line
(Mutu-3 Burkitt lymphoma cells) expressing lower, but detectable levels of LMP-1 and NF- $\kappa$ B showed an intermediate sensitivity to death by simvastatin. However, other EBV-positive cells (Akata, P3HR-1, and Mutu-1 Burkitt lymphoma cells) that expressed low levels of NF- $\kappa \mathrm{B}$ and no detectable LMP-1 were much less sensitive to simvastatin. One of these latter cell lines (P3HR-1) expressed levels of LFA-1 and ICAM-1 that were similar to those in EBVtransformed $\mathrm{B}$ cells. Taken together, these finding suggest that inhibition of NF- $\kappa$ B by simvastatin may be more important than its ability to block the interaction of LFA-1 with ICAM-1.

\section{Studies of simvastatin in an animal model of EBV lymphoma}

Intraperitoneal injection of EBV-transformed B cells into SCID mice results in development of EBV-positive lymphomas that resemble the tumours seen in immunosuppressed persons (Rowe et al, 1991). These tumours show a pattern of gene expression similar to that in patients with EBV lymphoproliferative disease with EBNAs, LMP-1, and adhesion molecules detected in the tumours.

Oral treatment of SCID mice with simvastatin beginning 3 days prior to injection with EBV-transformed B cells resulted in a statistically significant improvement in survival rate compared to animals not given the drug (Figure 3) (Katano et al, 2004). While there was a trend for longer survival for mice treated with simvastatin beginning 7 days after injection with EBV-transformed $B$ cells, the difference with untreated mice was not statistically significant. Some tumours from mice that were treated with simvastatin showed downregulation of LFA-1 on their surface, compared with the EBV-transformed B cells that had been used to inject the animals.

The dose of simvastatin used to treat these mice $\left(250 \mathrm{mg} \mathrm{kg}^{-1} \mathrm{day}^{-1}\right)$ is estimated to result in serum levels that would be 4 to 8 times that of humans receiving the maximum dose of simvastatin $\left(80 \mathrm{mg} \mathrm{day}^{-1}\right)$ used to lower serum cholesterol. However, similar high serum levels have been achieved in humans treated with large doses of statins in cancer therapy trials (see below).

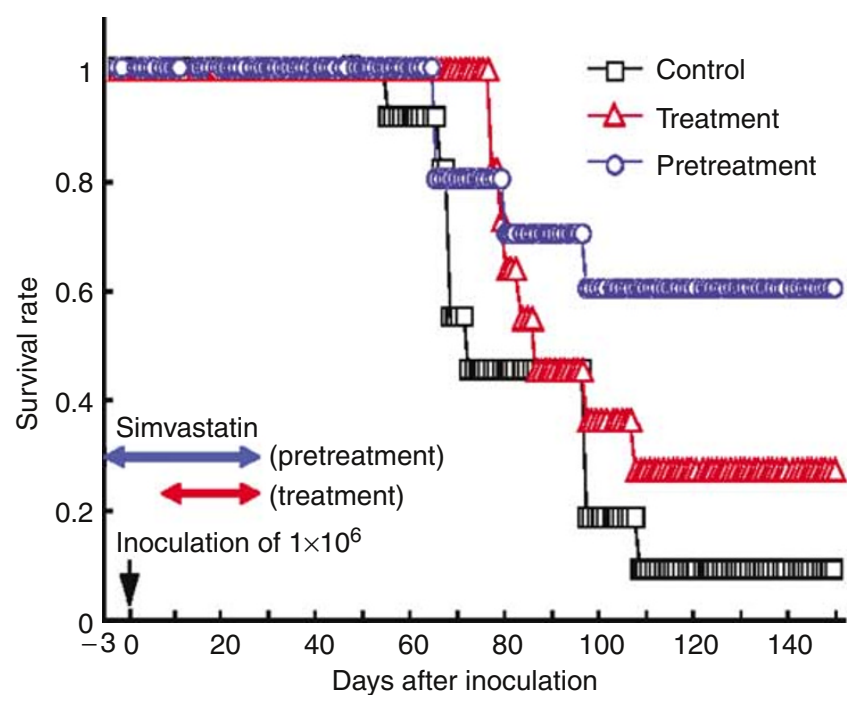

Figure 3 Simvastatin increases survival of SCID mice inoculated with EBV-transformed B cells. Mice treated with simvastatin before inoculation with EBV-transformed $B$ cells have improved survival $(P<0.04)$ compared with untreated mice. Mice treated with simvastatin after inoculation with virus-transformed B cells show a trend (not statistically significant) toward improved survival. Reproduced with permission from Katano et al (2004). 


\section{STATINS FOR TREATMENT OF OTHER TUMOURS}

Statins have been shown to induce apoptosis in several proliferating tumour cell lines, including certain leukaemia, lymphoma, astrocytoma, pancreatic carcinoma, and neuroblastoma cell lines (reviewed in Wong et al, 2002). This effect is due to inhibition of HMG-CoA reductase since it can be inhibited by mevalonate. Lovastatin reduced viability of EBV-positive or EBV-negative Burkitt lymphoma cells by $>75 \%$ due to inhibition of geranylgeranylation (van de Donk et al, 2003). Statins have been used in animal models and have reduced the tumour burden associated with melanoma, hepatoma, neuroblastoma, pancreatic cancer, and lung cancer (reviewed in Wong et al, 2002). In other animal models, statins have been used as adjunctive therapy in combination with cytotoxic agents in mouse models including carmustine for melanoma and with doxorubicin for lung cancer.

\section{Clinical studies of statins}

A number of studies have tested the role of oral statin therapy in patients with tumours (reviewed in Wong et al, 2002). Lovastatin given in doses ranging from 2 to $45 \mathrm{mg} \mathrm{kg}^{-1}$ day $^{-1}$ for 1 out of every 4 weeks was used to treat a variety of tumours including astrocytoma, glioblastoma, and prostate, breast, ovarian, and lung cancer (Thibault et al, 1996). Doses of $25 \mathrm{mg} \mathrm{kg}^{-1} \mathrm{day}^{-1}$ for 7 days were well tolerated. Serum levels of the drug ranged from 0.1 to $3.9 \mu \mathrm{M}$. One patient with an astrocytoma had a minor response to therapy. Since mice metabolise statins more rapidly than humans, a dose of $25 \mathrm{mg} \mathrm{kg}^{-1}$ day $^{-1}$ is comparable to $\sim 250 \mathrm{mg} \mathrm{kg}^{-1}$ day $^{-1}$ in mice.

While large doses of statins have been used in patients with cancer, might standard doses of statins prevent development of haematologic malignancies? Large trials of simvastatin for the prevention of coronary events have evaluated the incidence of cancer in study recipients. No significant decrease in the overall incidence of cancer or of haematologic malignancies was noted in the MRC/BHF Heart Protection Study involving 20536 patients randomised to $40 \mathrm{mg}$ of simvastatin per day or placebo for a median of 5 years (Heart Protection Study Group, 2002). Similarly, there was no significant decrease in the incidence or mortality for cancer, or for lymphatic or haematopoeitic malignancies in the Scandinavian Simvastatin Survival Study in which 4444 patients were randomised to simvastatin (20-40 mg per day) $v s$ placebo for a median of 5.4 years (Strandberg et al, 2004). Thus, simvastatin at the standard doses to prevent coronary events did not have a significant effect on the risk of haematologic cancers.

\section{TREATMENT OF EBV-DRIVEN LYMPHOMA}

EBV lymphomas occur in immunocompromised patients such as organ or stem cell transplant recipients, patients with HIV, or patients with congenital immunodeficiencies. These tumours generally express each of the EBV latency proteins and the tumours are driven by these viral proteins. Central nervous system lymphomas account for $20 \%$ of lymphomas in AIDS patients and express EBV LMP-1 and other latency proteins (MacMahon et al, 1991). Immunoblastic lymphomas account for about $60 \%$ of cases of lymphoma in patients with AIDS and usually express EBV LMP1 and other latency proteins (Hamilton-Dutoit et al, 1993). These tumours generally occur in AIDS patients late in the course of disease when $\mathrm{CD} 4+\mathrm{T}$ cell numbers are low.

Tumours in immunocompromised patients can occur in lymph nodes, but frequently present at extranodal sites such as the gastrointestinal tract, central nervous system, liver, lung, bone marrow, or transplanted organ (Cohen, 2000). The tumours can be polyclonal or monoclonal and usually lack chromosomal translo- cations. Patients who lack immunity to EBV at the time of transplant and develop primary EBV infection after transplant are more likely to develop EBV-driven lymphomas. Transplant recipients who receive HLA-mismatched or T-cell-depleted bone marrow or infusions of antilymphocyte antibodies for rejection are also at increased risk for development of lymphomas. EpsteinBarr virus viral DNA is often elevated in peripheral blood mononuclear cells of these patients prior to, and at the onset of lymphoma, indicative of the EBV-driven B-cell proliferation. Patients with these tumours have impaired T-cell immunity to EBV resulting in failure to regulate EBV-driven B-cell proliferation.

Treatment for these lymphomas includes reduction in immunosuppression when possible. Resection of localised lesions, especially in the gastrointestinal tract has been effective in some patients. Monoclonal anti-CD20 antibody (rituximab) results in remissions in about $50 \%$ of patients. Interferon- $\alpha$ has been effective in some patients, but may increase the risk of rejection of the transplanted organ. Lymphomas in stem cell transplant recipients are usually of donor origin; infusions of donor $\mathrm{T}$ cells (which are HLA-matched) have been effective in many cases of EBV lymphoma in these patients. Lymphomas in organ transplant recipients are usually recipient in origin; infusions of autologous or HLA-matched T cells have been effective. Radiation therapy, especially for central nervous system lesions, and cytotoxic chemotherapy are used for refractory cases. The latter two therapies are frequently used for lymphomas in AIDS patients whose immune systems are less responsive to immunologic-based therapies.

Statins may have a role as adjunctive therapy in some patients with EBV-driven lymphomas. These might include stem cell transplant recipients in whom donor $\mathrm{T}$ cells are not available, organ transplant recipients whose lymphomas are not responsive to reduction of immunosuppressive therapy and in whom HLAmatched $\mathrm{T}$ cells are not available. In these settings, statins might be used in combination with other therapies (e.g. rituximab or interferon- $\alpha$ ) which by themselves result in remissions in about $50 \%$ of patients. Statins might be tried in AIDS patients with EBVdriven lymphomas, especially those with very low CD4T cell counts who tend to respond less well to chemotherapy. Statins might also be considered for patients with EBV-positive Hodgkin's disease who are refractory to chemotherapy and radiation therapy. Tumours from these patients usually express LMP-1 as well as adhesion molecules (Sandvej et al, 1993), and statins might reduce the viability of the tumour cells. While nasopharyngeal carcinoma and T-cell lymphomas frequently express LMP-1, the tumours show more variable expression of the protein and therefore might be less susceptible to statins. Finally, Burkitt lymphomas do not express LMP-1 and therefore would be unlikely to respond to statins at doses that are effective for cells transformed with EBV in vitro.

\section{CONCLUSIONS}

Identification of signalling pathways for EBV-mediated transformation has helped to identify new targets and potential treatments for these tumours. Certain statins have been shown to inhibit the interactions of adhesion molecules and block NF- $\kappa \mathrm{B}$ activation in EBV-transformed cells, resulting in apoptosis. Simvastatin delays the development of EBV-lymphomas in SCID mice inoculated with EBV-transformed B cells. The dose of statin needed to induce apoptosis is much higher than that required for lowering serum cholesterol, but such doses have been tolerated by patients in clinical trials. Statins may have a role in the treatment of EBVdriven lymphomas, most likely as part of combination therapy for these lymphomas. 


\section{REFERENCES}

Anagnostopoulos I, Hummel M, Finn T, Tiemann M, Korbjuhn P, Dimmler C, Gatter K, Dallenbach F, Parwaresch MR, Stein H (1992) Heterogeneous Epstein-Barr virus infection patterns in peripheral T-cell lymphoma of angioimmunoblastic lymphadenopathy type. Blood 80: 1804-1812

Bellosta S, Ferri N, Bernini F, Paoletti R, Corsini A (2000) Non-lipid-related effects of statins. Ann Med 32: 164-176

Cahir-McFarland ED, Carter K, Rosenwald A, Giltnane JM, Henrickson SE, Staudt LM, Kieff E (2004) Role of NF-kappa B in cell survival and transcription of latent membrane protein 1-expressing or Epstein-Barr virus latency III-infected cells. J Virol 78: 4108-4119

Cahir-McFarland ED, Davidson DM, Schauer SL, Duong J, Kieff E (2000) NF-kappa B inhibition causes spontaneous apoptosis in Epstein-Barr virus-transformed lymphoblastoid cells. Proc Natl Acad Sci USA 97: $6055-6060$

Cohen JI (2000) Epstein - Barr virus infection. N Engl J Med 343: $481-492$

Corsini A, Mazzotti M, Raiteri M, Soma MR, Gabbiani G, Fumagalli R, Paoletti R (1993) Relationship between mevalonate pathway and arterial myocyte proliferation: in vitro studies with inhibitors of HMG-CoA reductase. Atherosclerosis 101: $117-125$

Dawson CW, Tramountanis G, Eliopoulos AG, Young LS (2003) Epstein Barr virus latent membrane protein 1 (LMP1) activates the phosphatidylinositol 3-kinase/Akt pathway to promote cell survival and induce actin filament remodeling. J Biol Chem 278: $3694-3704$

Deacon EM, Pallesen G, Niedobitek G, Crocker J, Brooks L, Rickinson AB, Young LS (1993) Epstein - Barr virus and Hodgkin's disease: transcriptional analysis of virus latency in the malignant cells. J Exp Med 177: $339-349$

del Real G, Jimenez-Baranda S, Mira E, Lacalle RA, Lucas P, GomezMouton C, Alegret M, Pena JM, Rodriguez-Zapata M, Alvarez-Mon M, Martinez-A C, Manes S (2004) Statins inhibit HIV-1 infection by downregulating Rho activity. J Exp Med 200: $541-547$

Devergne O, Hatzivassiliou O, Izumi KM, Kaye KM, Kleijnen MF, Kieff E, Mosialos G (1996) Association of TRAF1, TRAF2, and TRAF3 with an Epstein-Barr virus LMP1 domain important for B-lymphocyte transformation: role in NF-KB activation. Mol Cell Biol 16: $7098-7108$

Dykstra ML, Longnecker R, Pierce SK (2001) Epstein-Barr virus coopts lipid rafts to block the signaling and antigen transport functions of the BCR. Immunity 14: 57-67

Fahraeus R, Fu HL, Ernberg I, Finke J, Rowe M, Klein G, Falk K, Nilsson E, Yadav M, Busson P (1988) Expression of Epstein-Barr virus-encoded proteins in nasopharyngeal carcinoma. Int J Cancer 42: 329-338

Fortin J-F, Cantin R, Lamontagne G, Tremblay M (1997) Host-derived ICAM-1 glycoproteins incorporated on human immunodeficiency virus type 1 are biologically active and enhance viral infectivity. $J$ Virol 71: $3588-3596$

Giguere J-F, Tremblay M (2004) Statin compounds reduce human immunodeficiency virus type 1 replication by preventing the interactions between virus-associated host intercellular adhesion molecule 1 and natural cell surface ligand LFA-1. J Virol 78: $12062-12065$

Graaf MR, Richel DJ, van Noorden CJ, Guchelaar HJ (2004) Effects of statins and farnesyltransferase inhibitors on the development and progression of cancer. Cancer Treat Rev 30: 609-641

Hamilton-Dutoit SJ, Rea D, Raphael M, Sandvej K, Delecluse HJ, Gisselbrecht C, Marelle L, van Krieken HJ, Pallesen G (1993) Epstein Barr virus-latent gene expression and tumor cell phenotype in acquired immunodeficiency syndrome-related non-Hodgkin's lymphoma: correlation of lymphoma phenotype with three distinct patterns of viral latency. Am J Pathol 143: 1072-1085

Heart Protection Study Collaborative Group (2002) MRC/BHF Heart Protection Study of cholesterol lowering with simvastatin in 20,536 high-risk individuals: a randomised placebo-controlled trial. Lancet 360: 7-22

Higuchi M, Izumi KM, Kieff E (2001) Epstein-Barr virus latent-infection membrane proteins are palmitoylated and raft-associated: protein 1 binds to the cytoskeleton through TNF receptor cytoplasmic factors. Proc Natl Acad Sci USA 98: 4675-4680

Hillyard DZ, Cameron AJ, McDonald KJ, Thomson J, MacIntyre A, Shiels PG, Panarelli M, Jardine AG (2004) Simvastatin inhibits lymphocyte function in normal subjects and patients with cardiovascular disease. Atherosclerosis 175: $305-313$

Kallen J, Welzenbach K, Ramage P, Geyl D, Kriwacki R, Legge G, Cottens S, Weitz-Schmidt G, Hommel U (1999) Structural basis for LFA-1 inhibition upon lovastatin binding to the CD11a I-domain. J Mol Biol 292: $1-9$

Katano H, Pesnicak L, Cohen JI (2004) Simvastatin induces apoptosis of Epstein - Barr virus (EBV)-transformed lymphoblastoid cell lines and delays development of EBV lymphomas. Proc Natl Acad Sci USA 101: $4960-4965$

Kaykas A, Worringer K, Sugden B (2001) CD40 and LMP-1 both signal from lipid rafts but LMP-1 assembles a distinct, more efficient signaling complex. EMBO J 20: 2641 - 2654

Kieff E (2001) Epstein Barr virus and its replication. In Fields Virology Knipe DM, Howley PM (eds). 4th edn, Philadelphia: Lippincott Williams \& Wilkins, pp $2511-2573$

Kulwichit W, Edwards RH, Davenport EM, Baskir JF, Godfrey V, RaabTraub N (1998) Expression of the Epstein-Barr virus latent membrane protein 1 induces B cell lymphoma in transgenic mice. Proc Natl Acad Sci USA 95: $11963-11968$

Kurakata S, Kada M, Shimada Y, Komai T, Nomoto K (1996) Effects of different inhibitors of 3-hydroxy-3-methylglutaryl coenzyme A (HMG$\mathrm{CoA}$ ) reductase, pravastatin sodium and simvastatin, on sterol synthesis and immunological functions in human lymphocytes in vitro. Immunopharmacology 34: $51-61$

Kwak B, Mulhaupt F, Myit S, Mach F (2000) Statins as a newly recognized type of immunomodulator. Nat Med 6: 1399-1402

Liebowitz D (1998) Epstein - Barr virus and a cellular signaling pathway in lymphomas from immunosuppressed patients. $N$ Engl J Med 338: 1413 1421

MacMahon EME, Glass JD, Hayward SD, Mann RB, Becker PS, Charache P, McArthur JC, Ambinder RF (1991) Epstein - Barr virus in AIDS-related primary central nervous system lymphoma. Lancet 338: 969-973

Mundy G, Garrett R, Harris S, Chan J, Chen D, Rossini G, Boyce B, Zhao M, Gutierrez G (1999) Stimulation of bone formation in vitro and in rodents by statins. Science 286: $1946-1949$

Peng M, Lundgren E (1992) Transient expression of the Epstein - Barr virus LMP1 gene in human primary B cells induces cellular activation and DNA synthesis. Oncogene 7: 1775-1782

Perez OD, Mitchell D, Jager GC, South S, Murriel C, McBride J, Herzenberg LA, Kinoshita S, Nolan GP (2003) Leukocyte functional antigen 1 lowers $\mathrm{T}$ cell activation thresholds and signaling through cytohesin-1 and Junactivating binding protein 1. Nat Immunol 4: 1083-1092

Raggatt LJ, Partridge NC (2002) HMG-CoA reductase inhibitors as immunomodulators: potential use in transplant rejection. Drugs 62: $2185-2191$

Ramalingam P, Chu WS, Tubbs R, Rybicki L, Pettay J, Hsi ED (2003) Latent membrane protein 1, tumor necrosis factor receptor-associated factor (TRAF) 1, TRAF-2, TRAF-3, and nuclear factor kappa B expression in posttransplantation lymphoproliferative disorders. Arch Pathol Lab Med 127: $1335-1339$

Rowe M, Rowe DT, Gregory CD, Young LS, Farrell PJ, Rupani H, Rickinson AB (1987) Differences in B cell growth phenotype reflect novel patterns of Epstein-Barr virus latent gene expression in Burkitt's lymphoma cells. EMBO J 6: $2743-2751$

Rowe M, Young LS, Crocker J, Stokes H, Henderson S, Rickinson AB (1991) Epstein - Barr virus (EBV)-associated lymphoproliferative disease in the SCID mouse model: implications for the pathogenesis of EBV-positive lymphomas in man. J Exp Med 173: $147-158$

Sandvej KB, Hamilton-Dutoit SJ, Pallesen G (1993) Influence of EpsteinBarr virus encoded latent membrane protein 1 on the expression of CD23 antigen, ICAM-1 and LFA-3 in Hodgkin and Reed-Sternberg cells. A morphometric analysis. Leuk Lymphoma 9: 95-101

Speck P, Kline KA, Cheresh P, Longnecker R (1999) Epstein-Barr virus lacking latent membrane protein 2 immortalizes B cells with efficiency indistinguishable from that of wild-type virus. J Gen Virol 80: 2193-2203

Strandberg TE, Pyorala K, Cook TJ, Wilhelmsen L, Faergeman O, Thorgeirsson G, Pedersen TR, Kjekshus J, 4S Group (2004) Mortality and incidence of cancer during 10-year follow-up of the Scandinavian Simvastatin Survival Study (4S). Lancet 364: $771-777$

Thibault A, Samid D, Tompkins AC, Figg WD, Cooper MR, Hohl RJ, Trepel J, Liang B, Patronas N, Venzon DJ, Reed E, Myers CE (1996) Phase I study of lovastatin, an inhibitor of the mevalonate pathway, in patients with cancer. Clin Cancer Res 2: 483-491

van de Donk NW, Schotte D, Kamphuis MM, van Marion AM, van Kessel B, Bloem AC, Lokhorst HM (2003) Protein geranylgeranylation is critical 
for the regulation of survival and proliferation of lymphoma tumor cells. Clin Cancer Res 9: 5735-5748

Waehre T, Damas JK, Gullestad L, Holm AM, Pedersen TR, Arnesen KE, Torsvik H, Froland SS, Semb AG, Aukrust P (2003) Hydroxymethylglutaryl coenzyme a reductase inhibitors down-regulate chemokines and chemokine receptors in patients with coronary artery disease. J Am Coll Cardiol 41: 1460-1467

Wang F, Gregory C, Sample C, Rowe M, Liebowitz D, Murray R, Rickinson A, Kieff E (1990) Epstein-Barr virus latent membrane protein (LMP-1) and nuclear proteins 2 and $3 \mathrm{C}$ are effectors of phenotypic changes in B lymphocytes: EBNA-2 and LMP-1 cooperatively induce CD23. J Virol 64: 2309-2318
Weitz-Schmidt G, Welzenbach K, Brinkmann V, Kamata T, Kallen J, Bruns C, Cottens S, Takada Y, Hommel U (2001) Statins selectively inhibit leukocyte function antigen-1 by binding to a novel regulatory integrin site. Nat Med 7: 687-692

Wong WW, Dimitroulakos J, Minden MD, Penn LZ (2002) HMG-CoA reductase inhibitors and the malignant cell: the statin family of drugs as triggers of tumor-specific apoptosis. Leukemia 16: 508-519

Yasui T, Luftig M, Soni V, Kieff E (2004) Latent infection membrane protein transmembrane FWLY is critical for intermolecular interaction, raft localization, and signaling. Proc Natl Acad Sci USA 101: $278-283$ 